\title{
Some unique fixed point theorems for rational contractions in partially ordered metric spaces
}

\author{
Muhammad Arshad $^{1 *}$, Erdal Karapınar ${ }^{2}$ and Jamshaid Ahmad $^{3}$
}

\section{"Correspondence:}

marshad_zia@yahoo.com

'Department of Mathematics, International Islamic University,

H-10, Islamabad, 44000, Pakistan Full list of author information is

available at the end of the article

\begin{abstract}
In this paper, we prove some unique fixed point results for an operator $T$ satisfying certain rational contraction condition in a partially ordered metric space. Our results generalize the main result of Jaggi (Indian J. Pure Appl. Math. 8(2):223-230, 1977). We give several examples to show that our results are proper generalization of the existing one.
\end{abstract}

MSC: $47 \mathrm{H} 10 ; 54 \mathrm{H} 25 ; 46 \mathrm{~J} 10 ; 46 \mathrm{~J} 15$

Keywords: fixed point; rational contractions; partially ordered metric spaces

\section{Introduction}

Fixed point theory is one of the famous and traditional theories in mathematics and has a broad set of applications. In this theory, contraction is one of the main tools to prove the existence and uniqueness of a fixed point. Banach's contraction principle, which gives an answer on the existence and uniqueness of a solution of an operator equation $T x=x$, is the most widely used fixed point theorem in all of analysis. This principle is constructive in nature and is one of the most useful tools in the study of nonlinear equations. There are many generalizations of Banach's contraction mapping principle in the literature [1-6]. These generalizations were made either by using the contractive condition or by imposing some additional conditions on an ambient space. There have been a number of generalizations of metric spaces such as rectangular metric spaces, pseudo metric spaces, fuzzy metric spaces, quasi metric spaces, quasi semi-metric spaces, probabilistic metric spaces, $D$-metric spaces and cone metric spaces

The basic topological properties of ordered sets were discussed by Wolk [7] and Monjardet [8]. The existence of fixed points in partially ordered metric spaces was considered by Ran and Reurings [9]. After this paper, Nieto et al. [10-12] published some new results. Recently, many papers have been reported on partially ordered metric spaces (see, e.g., [9-19] and also [8, 20-33]).

The triple $(X, d, \preceq)$ is called partially ordered metric spaces (POMS) if $(X, \preceq)$ is a partially ordered set and $(X, d)$ is a metric space. Further, if $(X, d)$ is a complete metric space, the triple $(X, d, \leq)$ is called partially ordered complete metric spaces (POCMS). Throughout the manuscript, we assume that $X \neq \emptyset$. A partially ordered metric space $(X, d, \preceq)$ is called ordered complete (OC) if for each convergent sequence $\left\{x_{n}\right\}_{n=0}^{\infty} \subset X$, the following condition holds: either

(c) 2013 Arshad et al.; licensee Springer. This is an Open Access article distributed under the terms of the Creative Commons Attribution License (http://creativecommons.org/licenses/by/2.0), which permits unrestricted use, distribution, and reproduction in any medium, provided the original work is properly cited. 
- if $\left\{x_{n}\right\}$ is a non-increasing sequence in $X$ such that $x_{n} \rightarrow x^{*}$ implies $x^{*} \preceq x_{n} \forall n \in \mathbb{N}$, that is, $x^{*}=\inf \left\{x_{n}\right\}$, or

- if $\left\{x_{n}\right\}$ is a non-decreasing sequence in $X$ such that $x_{n} \rightarrow x^{*}$ implies $x_{n} \preceq x^{*} \forall n \in \mathbb{N}$, that is, $x^{*}=\sup \left\{x_{n}\right\}$.

In this manuscript, we prove that an operator $T$ satisfying certain rational contraction condition has a fixed point in a partially ordered metric space. Our results generalize the main result of Jaggi [34].

\section{Main results}

We start this section with the following definition.

Definition 1 Let $(X, d, \preceq)$ be a partially ordered metric space. A self-mapping $T$ on $X$ is called an almost Jaggi contraction if it satisfies the following condition:

$$
d(T x, T y) \leq \frac{\alpha d(x, T x) \cdot d(y, T y)}{d(x, y)}+\beta d(x, y)+L \min \{d(x, T y), d(y, T x)\}
$$

for any distinct $x, y \in X$ with $x \preceq y$, where $L \geq 0$ and $\alpha, \beta \in[0,1)$ with $\alpha+\beta<1$.

Theorem 2 Let $(X, d, \preceq)$ be a complete partially ordered metric space. Suppose that a selfmapping $T$ is an almost Jaggi contraction, continuous and non-decreasing. Suppose there exists $x_{0} \in X$ with $x_{0} \preceq T x_{0}$. Then $T$ has a unique fixed point.

Proof Let $x_{0} \in X$ and set $x_{n+1}=T x_{n}$. If $x_{n_{0}}=x_{n_{0}+1}$ for some $n_{0} \in \mathbb{N}$, then $T$ has a fixed point. In particular, $x_{n_{0}}$ is a fixed point of $T$. So, we assume that $x_{n} \neq x_{n+1}$ for all $n$. Since $x_{0} \preceq T x_{0}$, then

$$
x_{0} \preceq x_{1} \preceq \cdots \preceq x_{n} \preceq x_{n+1} \preceq \cdots .
$$

Now

$$
\begin{aligned}
d\left(x_{n+1}, x_{n}\right)= & d\left(T x_{n}, T x_{n-1}\right) \\
\leq & \frac{\alpha d\left(x_{n-1}, T x_{n-1}\right) d\left(x_{n}, T x_{n}\right)}{d\left(x_{n}, x_{n-1}\right)}+\beta d\left(x_{n}, x_{n-1}\right) \\
& +L \min \left\{d\left(x_{n}, x_{n}\right), d\left(x_{n-1}, x_{n+1}\right)\right\}
\end{aligned}
$$

which implies that

$$
d\left(x_{n+1}, x_{n}\right) \leq\left(\frac{\beta}{1-\alpha}\right) d\left(x_{n}, x_{n-1}\right) \leq \cdots \leq\left(\frac{\beta}{1-\alpha}\right)^{n} d\left(x_{1}, x_{0}\right) .
$$

By the triangle inequality, for $m \geq n$ we have

$$
\begin{aligned}
d\left(x_{n}, x_{m}\right) & \leq d\left(x_{n}, x_{n+1}\right)+d\left(x_{n+1}, x_{n+2}\right)+\cdots+d\left(x_{m-1}, x_{m}\right) \\
& \leq\left(k^{n}+k^{n+1}+\cdots+k^{m-1}\right) d\left(x_{0}, T x_{0}\right) \\
& \leq \frac{k^{n}}{1-k} d\left(x_{0}, T x_{0}\right)
\end{aligned}
$$


where $k=\frac{\beta}{1-\alpha}$. Letting $n \rightarrow \infty$ in the inequality (3), we get $d\left(x_{n}, x_{m}\right)=0$. Thus, the sequence $\left\{x_{n}\right\}$ is Cauchy. Since $X$ is complete, there exists a point $z \in X$ such that $x_{n} \rightarrow z$. Furthermore, the continuity of $T$ in $X$ implies that

$$
\begin{aligned}
T z & =T\left(\lim _{n \rightarrow \infty} x_{n}\right) \\
& =\lim _{n \rightarrow \infty} T x_{n} \\
& =\lim _{n \rightarrow \infty} x_{n+1} \\
& =z .
\end{aligned}
$$

Therefore, $z$ is a fixed point of $T$ in $X$. Now, if there exists another point $w \neq z$ in $X$ such that $T w=w$, then

$$
\begin{aligned}
d(w, z) & =d(T w, T z) \\
& \leq \frac{\alpha d(w, T w) \cdot d(z, T z)}{d(w, z)}+\beta d(w, z) \\
& =\beta d(w, z)<d(w, z),
\end{aligned}
$$

a contradiction. Hence $u$ is a unique fixed point of $T$ in $X$.

Example 3 Let $X=[0,1]$ with the usual metric and usual order $\leq$. We define an operator $T: X \rightarrow X$ as follows:

$$
T x= \begin{cases}\frac{x}{10} & \text { if } x \in\left[0, \frac{1}{2}\right], \\ \frac{x}{5}-\frac{1}{20} & \text { if } x \in\left(\frac{1}{2}, 1\right] .\end{cases}
$$

Then $T$ is continuous and non-decreasing. Take $\beta=\frac{1}{4}$. Then, for any $\alpha \in[0,1)$ with $\alpha+\beta<$ 1 , we have the result. Let us examine in detail. Without loss of generality, we assume that $y \preceq x$.

Case 01. If $x, y \in\left[0, \frac{1}{2}\right]$, then

$$
\begin{aligned}
d(T x, T y) & =\frac{1}{10}|x-y| \\
& \leq \frac{1}{4}|x-y|=\frac{1}{4} d(x, y) \\
& \leq \frac{\alpha d(x, T x) \cdot d(y, T y)}{d(x, y)}+\frac{1}{4} d(x, y)+L \min \{d(x, T y), d(y, T x)\}
\end{aligned}
$$

holds for any $L \geq 1$ and any $\alpha \in[0,1)$ with $\alpha+\beta<1$. Thus, all the conditions of Theorem 2 are satisfied.

Case 02 . If $x, y \in\left(\frac{1}{2}, 1\right]$, then

$$
\begin{aligned}
d(T x, T y) & =\frac{1}{5}|x-y| \\
& \leq \frac{1}{4}|x-y|=\frac{1}{4} d(x, y) \\
& \leq \frac{\alpha d(x, T x) \cdot d(y, T y)}{d(x, y)}+\frac{1}{4} d(x, y)+L \min \{d(x, T y), d(y, T x)\}
\end{aligned}
$$


holds for any $L \geq 0$ and any $\alpha \in[0,1)$ with $\alpha+\beta<1$. Hence, all the conditions of Theorem 2 are satisfied.

Case 03. If $x \in\left(\frac{1}{2}, 1\right]$ and $y \in\left[0, \frac{1}{2}\right]$, then we can easily evaluate that $\frac{1}{20}|2 x-1| \leq \frac{1}{20}$. Further, we have $\frac{9}{20} \leq d(x, T y)=\left|x-\frac{y}{10}\right| \leq 1$ and $\frac{3}{20} \leq d(y, T x)=\left|\frac{x}{5}-\frac{1}{20}-y\right| \leq \frac{9}{20}$. By the help of these observations, we derive that

$$
\begin{aligned}
d(T x, T y) & =\left|\frac{x}{5}-\frac{1}{20}-\frac{y}{10}\right|=\left|\frac{x}{10}-\frac{y}{10}+\frac{x}{10}-\frac{1}{20}\right| \\
& \leq \frac{1}{10}|x-y|+\frac{1}{20}|2 x-1| \\
& \leq \frac{\alpha d(x, T x) \cdot d(y, T y)}{d(x, y)}+\frac{1}{4} d(x, y)+L \min \{d(x, T y), d(y, T x)\} .
\end{aligned}
$$

Notice that $0 \in X$ is the fixed point of $T$.

Definition 4 Let $(X, d, \preceq)$ be a partially ordered metric space. A self-mapping $T$ on $X$ is called a Jaggi contraction if it satisfies the following condition:

$$
d(T x, T y) \leq \frac{\alpha d(x, T x) \cdot d(y, T y)}{d(x, y)}+\beta d(x, y)
$$

for any distinct $x, y \in X$ with $x \preceq y$, where $\alpha, \beta \in[0,1)$ with $\alpha+\beta<1$.

Corollary 5 Let $(X, d, \preceq)$ be a complete partially ordered metric space. Suppose that a selfmapping $T$ is a Jaggi contraction, continuous and non-decreasing. Suppose that there exists $x_{0} \in X$ with $x_{0} \preceq T x_{0}$. Then $T$ has a fixed point.

Proof Set $L=0$ in Theorem 2 .

Example 6 Let $X=[0, \infty), d: X \times X \rightarrow \mathbb{R}_{+}$be defined by

$$
d(x, y)= \begin{cases}\max \{x, y\} & \text { if } x \neq y \\ 0 & \text { if } x=y\end{cases}
$$

Then $(X, d)$ is a complete metric space. Let $T: X \rightarrow X$ be defined by

$$
T x= \begin{cases}\frac{x}{8(1+x)} & \text { if } 0 \leq x \leq 2, \\ \frac{x}{12} & \text { if } 2<x .\end{cases}
$$

Also, $x \preceq y$ iff $x \leq y$. Clearly, $T$ is an increasing and continuous self-mapping on $X$. We shall prove that conditions of Corollary 5 hold and $T$ has a fixed point.

Proof For the proof of this example, we have the following cases. 
- Let $0 \leq x<y \leq 2$. Then

$$
\begin{aligned}
d(T x, T y) & =\max \{T x, T y\}=\frac{y}{8(1+y)} \leq \frac{1}{4}(x+y)=\frac{1}{4}\left(\frac{x y}{y}+y\right) \\
& =\frac{1}{4}\left[\frac{\max \left\{x, \frac{x}{8(1+x)}\right\} \max \left\{y, \frac{y}{8(1+y)}\right\}}{\max \{x, y\}}+\max \{x, y\}\right] \\
& =\frac{1}{4}\left(\frac{d(x, T x) d(y, T y)}{d(x, y)}+d(x, y)\right),
\end{aligned}
$$

that is,

$$
d(T x, T y) \leq \frac{1}{4} \frac{d(x, T x) d(y, T y)}{d(x, y)}+\frac{1}{4} d(x, y)
$$

- Let $2<x<y$. Then

$$
\begin{aligned}
d(T x, T y) & =\max \{T x, T y\}=\frac{y}{12} \leq \frac{1}{4}(x+y)=\frac{1}{4}\left(\frac{x y}{y}+y\right) \\
& =\frac{1}{4}\left[\frac{\max \left\{x, \frac{x}{12}\right\} \max \left\{y, \frac{y}{12}\right\}}{\max \{x, y\}}+\max \{x, y\}\right] \\
& =\frac{1}{4}\left(\frac{d(x, T x) d(y, T y)}{d(x, y)}+d(x, y)\right),
\end{aligned}
$$

that is,

$$
d(T x, T y) \leq \frac{1}{4} \frac{d(x, T x) d(y, T y)}{d(x, y)}+\frac{1}{4} d(x, y)
$$

- Let $0 \leq x \leq 2$ and $2<y$. Then

$$
\begin{aligned}
d(T x, T y) & =\max \{T x, T y\}=\frac{y}{12} \leq \frac{1}{4}(x+y)=\frac{1}{4}\left(\frac{x y}{y}+y\right) \\
& =\frac{1}{4}\left[\frac{\max \left\{x, \frac{x}{8(1+x)}\right\} \max \left\{y, \frac{y}{12}\right\}}{\max \{x, y\}}+\max \{x, y\}\right] \\
& =\frac{1}{4}\left(\frac{d(x, T x) d(y, T y)}{d(x, y)}+d(x, y)\right),
\end{aligned}
$$

that is,

$$
d(T x, T y) \leq \frac{1}{4} \frac{d(x, T x) d(y, T y)}{d(x, y)}+\frac{1}{4} d(x, y)
$$

Then conditions of Corollary 5 hold and $T$ has a fixed point (here, $x=0$ is a fixed point of $T)$.

In the next theorem, we establish the existence of a unique fixed point of a map $T$ by assuming only the continuity of some iteration of $T$. 
Theorem 7 Let $(X, d, \preceq)$ be a complete partially ordered metric space. Suppose that a selfmapping $T$ is non-decreasing and an almost Jaggi contraction. Suppose there exists $x_{0} \in X$ with $x_{0} \preceq T x_{0}$. If the operator $T^{p}$ is continuous for some positive integer $p$, then $T$ has a unique fixed point.

Proof As in Theorem 2, we define a sequence $x_{n}$ and conclude that the sequence $x_{n}$ converges to some point $z \in X$. Thus its subsequence $x_{n_{k}}\left(n_{k}=k p\right)$ also converges to $z$. Also,

$$
\begin{aligned}
T^{p} z & =T^{p}\left(\lim _{k \rightarrow \infty} x_{n_{k}}\right) \\
& =\lim _{k \rightarrow \infty} x_{n_{k+1}} \\
& =z .
\end{aligned}
$$

Therefore $z$ is a fixed point of $T^{p}$. We now show that $T z=z$. Let $m$ be the smallest positive integer such that $T^{m} z=z$ but $T^{q} \neq z(q=1,2, \ldots, m-1)$. If $m>1$, then

$$
\begin{aligned}
d(T z, z)= & d\left(T z, T^{m} z\right) \\
\leq & \frac{\alpha d(z, T z) \cdot d\left(T^{m-1} z, T^{m} z\right)}{d\left(z, T^{m-1} z\right)}+\beta d\left(z, T^{m-1} z\right) \\
& +L \min \left\{d\left(z, T^{m} z\right), d\left(T^{m-1} z, T z\right)\right\}
\end{aligned}
$$

which implies that

$$
d(T z, z) \leq \frac{\beta}{1-\alpha} d\left(z, T^{m-1} z\right) .
$$

Regarding (1), we have

$$
\begin{aligned}
d\left(z, T^{m-1} z\right)= & d\left(T^{m} z, T^{m-1} z\right) \\
\leq & \frac{\alpha d\left(T^{m-1} z, T^{m} z\right) \cdot d\left(T^{m-2} z, T^{m-1} z\right)}{d\left(T^{m-2} z, T^{m-1} z\right)} \\
& +\beta d\left(T^{m-1} z, T^{m-2} z\right) .
\end{aligned}
$$

Inductively, we get

$$
d\left(z, T^{m-1} z\right)=d\left(T^{m} z, T^{m-1} z\right) \leq k d\left(T^{m-1} z, T^{m-2} z\right) \leq \cdots \leq k^{m-1} d(T z, z),
$$

where $k=\frac{\beta}{1-\alpha}$. Notice that $k<1$. Therefore,

$$
d(T z, z) \leq k^{m} d(T z, z) \leq d(T z, z)
$$

a contradiction. Hence $T z=z$. The uniqueness of $z$ follows as in Theorem 2 .

Corollary 8 Let $(X, d, \preceq)$ be a complete partially ordered metric space. Suppose that a self-mapping $T$ is non-decreasing and a Jaggi contraction. Suppose there exists $x_{0} \in X$ with $x_{0} \preceq T x_{0}$. If the operator $T^{p}$ is continuous for some positive integer $p$, then $T$ has a unique fixed point. 
Proof Set $L=0$ in Theorem 7.

The following theorem generalizes Theorem 2 .

Theorem 9 Let $(X, d, \preceq)$ be a complete partially ordered metric space and let $T$ be a non-decreasing self-mapping defined on X. Suppose that for some positive integer $m$, selfmapping $T$ satisfies the following condition:

$$
d\left(T^{m} x, T^{m} y\right) \leq \frac{\alpha d\left(x, T^{m} x\right) \cdot d\left(y, T^{m} y\right)}{d(x, y)}+\beta d(x, y)+L \min \{d(x, T y), d(y, T x)\}
$$

for any distinct $x, y \in X$ with $x \preceq y$ and for some $\alpha, \beta \in[0,1)$ with $\alpha+\beta<1$ and $L \geq 0$. Suppose there exists $x_{0} \in X$ with $x_{0} \preceq T^{m} x_{0}$. If $T^{m}$ is continuous, then $T$ has a unique fixed point.

Proof Due to Theorem 2, we conclude that $T^{m}$ has a unique fixed point, say $z \in X$. Consider now

$$
T z=T\left(T^{m} z\right)=T^{m}(T z)
$$

Thus, $T z$ is also a fixed point of $T^{m}$. But, by Theorem 2, we know that $T^{m}$ has a unique fixed point $z$. It follows that $z=T z$. Hence, $z$ is the unique fixed point of $T$.

Corollary 10 Let $(X, d, \preceq)$ be a complete partially ordered metric space and let $T$ be a non-decreasing self-mapping defined on X. Suppose that for some positive integer $m$, the self-mapping $T$ satisfies the following condition:

$$
d\left(T^{m} x, T^{m} y\right) \leq \frac{\alpha d\left(x, T^{m} x\right) \cdot d\left(y, T^{m} y\right)}{d(x, y)}+\beta d(x, y)
$$

for all distinct $x, y \in X$ and for some $\alpha, \beta \in[0,1)$ with $\alpha+\beta<1$. Suppose there exists $x_{0} \in X$ with $x_{0} \preceq T^{m} x_{0}$. If $T^{m}$ is continuous, then $T$ has a unique fixed point.

Proof Set $L=0$ in Theorem 9.

Now, we give the following example.

Example 11 Let $X=[0,1]$ with the usual metric and usual order $\leq$. We define an operator $T: X \leftarrow X$ as follows:

$$
T x= \begin{cases}0, & x \in\left[0, \frac{1}{3}\right] \\ \frac{1}{3}, & x \in\left(\frac{1}{3}, 1\right]\end{cases}
$$

It can be easily seen that $T$ is discontinuous and does not satisfy (1) for any $\alpha, \beta \in[0,1)$ with $\alpha+\beta \prec 1$ when $x=\frac{1}{3}, y=1$. Now $T^{2}(x)=0$ for all $x \in[0,1]$. It can be verified that $T^{2}$ satisfies the conditions of Theorem 9 and 0 is a unique fixed point of $T^{2}$. 
Theorem 12 Let $(X, d, \preceq)$ be a complete partially ordered metric space and let $T$ be a non-decreasing self-mapping defined on $X$. Suppose that a self-mapping $T$ on $X$ satisfies the condition

$$
d(T x, T y) \leq \frac{\alpha d(T y, y)[1+d(x, T x)]}{1+d(x, y)}+\beta d(x, y)+L \min \{d(x, T x), d(x, T y), d(y, T x)\}
$$

for any points $x, y \in X$ with $x \preceq y$, and for some $\alpha, \beta \in[0,1)$ with $\alpha+\beta<1$ and $L \geq 0$. Suppose there exists $x_{0} \in X$ with $x_{0} \preceq T x_{0}$. Then $T$ has a fixed point.

Proof Define sequences $x_{n}$ as in Theorem 2. If $x_{n_{0}}=x_{n_{0}+1}$ for some $n_{0} \in \mathbb{N}$ then $T$ has a fixed point. In particular, $x_{n_{0}}$ is a fixed point of $T$. Therefore, we assume that

$$
x_{n} \neq x_{n+1} \quad \text { for all } n \in \mathbb{N} \text {. }
$$

Due to (7), we have

$$
\begin{aligned}
d\left(x_{n}, x_{n+1}\right)= & d\left(T x_{n-1}, T x_{n}\right) \\
\leq & \frac{\alpha d\left(x_{n}, T x_{n}\right)\left[1+d\left(x_{n-1}, T x_{n-1}\right)\right]}{1+d\left(x_{n-1}, x_{n}\right)}+\beta d\left(x_{n-1}, x_{n}\right) \\
& +L \min \left\{d\left(T x_{n-1}, x_{n-1}\right), d\left(x_{n-1}, T x_{n}\right), d\left(x_{n}, T x_{n-1}\right)\right\} \\
= & \frac{\alpha d\left(x_{n+1}, x_{n}\right)\left[1+d\left(x_{n}, x_{n-1}\right)\right]}{1+d\left(x_{n-1}, x_{n}\right)}+\beta d\left(x_{n-1}, x_{n}\right), \\
& +L \min \left\{d\left(x_{n-1}, x_{n}\right), d\left(x_{n-1}, x_{n+1}\right), d\left(x_{n}, x_{n}\right)\right\},
\end{aligned}
$$

which implies that

$$
d\left(x_{n+1}, x_{n}\right) \leq\left(\frac{\beta}{1-\alpha}\right) d\left(x_{n}, x_{n-1}\right) \text {. }
$$

Recursively, we obtain that

$$
d\left(x_{n+1}, x_{n}\right) \leq\left(\frac{\beta}{1-\alpha}\right)^{n} d\left(x_{1}, x_{0}\right)
$$

As in Theorem 2, we prove that $\left\{x_{n}\right\}$ is a Cauchy sequence. Indeed, by the triangle inequality, we have for $m \geq n$,

$$
\begin{aligned}
d\left(x_{n}, x_{m}\right) & \leq d\left(x_{n}, x_{n+1}\right)+d\left(x_{n+1}, y_{n+2}\right)+\cdots+d\left(x_{m-1}, x_{m}\right) \\
& \leq\left(k^{n}+k^{n+1}+\cdots+k^{m-1}\right) d\left(x_{0}, T x_{0}\right) \\
& \leq \frac{k^{n}}{1-k} d\left(x_{0}, x_{1}\right)
\end{aligned}
$$

where $k=\frac{\beta}{1-\alpha}<1$. Letting $n \rightarrow \infty$, then the right-hand side of the inequality (9) tends to 0 . Thus, the sequence $\left\{x_{n}\right\}$ is Cauchy.

Since $X$ is complete, there exists a $z \in X$ such that

$$
\lim _{n \rightarrow \infty} x_{n}=\lim _{n \rightarrow \infty} T x_{n}=z
$$


Consider (7)

$$
\begin{aligned}
d\left(T z, x_{n+1}\right)= & d\left(T z, T x_{n}\right) \\
\leq & \frac{\alpha d(z, T z)\left[1+d\left(x_{n}, T x_{n}\right)\right]}{1+d\left(z, x_{n}\right)}+\beta d\left(z, T x_{n}\right) \\
& +L \min \left\{d(z, T z), d\left(z, T x_{n}\right), d\left(x_{n}, T z\right)\right\} .
\end{aligned}
$$

Letting $n \rightarrow \infty$ in (11), we get

$$
\begin{aligned}
d(T z, z) & \leq \frac{\alpha d(z, T z)[1+d(z, z)]}{1+d(z, z)}+\beta d(z, z) \\
& =\alpha d(T z, z)
\end{aligned}
$$

which is possible only if $d(T z, z)=0$. Thus, $T z=z$.

Now, we show that $z$ is the unique fixed point of $T$. Assume, on the contrary, that the operator $T$ has another fixed point $u \neq z$. Keeping (7) in mind, we obtain that

$$
\begin{aligned}
d(z, u)= & d(T z, T u) \\
\leq & \frac{\alpha d(T u, u)[1+d(z, T z)]}{1+d(z, u)}+\beta d(z, u) \\
& +L \min \{d(z, T z), d(z, T u), d(u, T z)\} \\
= & \frac{\alpha d(u, u) \cdot[1+d(z, z)]}{d(z, u)}+\beta d(z, u) \\
= & \beta d(z, u),
\end{aligned}
$$

a contradiction. Hence $z$ is a unique fixed point of $T$ in $X$.

Corollary 13 Let $(X, d, \preceq)$ be a complete partially ordered metric space and let $T$ be a non-decreasing self-mapping defined on $X$. Suppose that a self-mapping $T$ on $X$ satisfies the condition

$$
d(T x, T y) \leq \frac{\alpha d(T y, y)[1+d(x, T x)]}{1+d(x, y)}+\beta d(x, y)
$$

for any points $x, y \in X$ with $x \preceq y$, and for some $\alpha, \beta \in[0,1)$ with $\alpha+\beta<1$. Then $T$ has a fixed point.

Proof Set $L=0$ in Theorem 12 .

Example 14 Let $X=[0,1], d: X \times X \rightarrow \mathbb{R}_{+}$be defined by

$$
d(x, y)=|x-y|
$$

Then $(X, d)$ is a complete metric space. Let $T: X \rightarrow X$ be defined by

$$
T x=\frac{1}{6} x^{3}
$$


Also, $x \preceq y$ iff $x \leq y$. Suppose that $\beta=\frac{1}{3}$ and $\alpha \in[0,1)$ such that $\alpha+\beta<1$. Clearly, $T$ is an injective, continuous and sequentially convergent mapping on $X$. We shall prove that conditions of Corollary 8 hold and $T$ has a fixed point.

Proof For the proof of this example, we have the following cases.

Let $x, y \in[0,1]$. Then

$$
d(T x, T y)=\frac{1}{6}\left|x^{3}-y^{3}\right|=\frac{1}{6}\left|(x-y)\left(x^{2}+x y+y^{2}\right)\right| \leq \frac{1}{3}|x-y|=\frac{1}{3} d(x, y) .
$$

That is,

$$
d(T x, T y) \leq \alpha \frac{d(y, T y)[1+d(x, T x)]}{1+d(x, y)}+\beta d(x, y) .
$$

Hence, conditions of Corollary 8 hold and $T$ has a fixed point (here $x=0$ is a fixed point of $T)$.

\section{Further results}

Theorem 15 Let $(X, d, \preceq)$ be a complete partially ordered metric space and let $T$ be a nondecreasing, continuous self-mapping defined on X. Suppose that a self-mapping $T$ satisfies the following condition:

$$
d(T x, T y) \leq \begin{cases}\lambda d(x, y)+\mu \frac{d(x, T x) d(x, T y)+d(y, T x) d(y, T y)}{d(y, T x)+d(x, T y)} & \text { if } A \neq 0, \\ 0 & \text { if } A=0,\end{cases}
$$

for all $x, y \in X$ with $y \preceq x$, where $A=d(y, T x)+d(x, T y)$ and $\lambda, \mu$ are non-negative reals such that $\lambda+\mu<1$. If there exists $x_{0} \in X$ with $x_{0} \preceq T x_{0}$, then $T$ has a fixed point.

Proof By assumption, there exists $x_{0} \in X$ with $x_{0} \preceq T x_{0}$. If $x_{0}=T x_{0}$, then the proof is finished. So, we suppose that $x_{0} \prec T x_{0}$. Since $T$ is a non-decreasing mapping, we get

$$
x_{0} \prec T x_{0} \preceq T^{2} x_{0} \preceq \cdots \preceq T^{n} x_{0} \preceq T^{n+1} x_{0} \preceq \cdots
$$

by iteration. Put $x_{n+1}=T x_{n}$. If there exists $n_{0} \in N$ such that $x_{n_{0}}=x_{n_{0}+1}$, then from $x_{n_{0}}=$ $x_{n_{0}+1}=T x_{n_{0}}$, we get $x_{n_{0}}$ is a fixed point, and the proof is finished. Suppose that $x_{n} \neq x_{n+1}$ for $n \in N$. Since the points $x_{n}$ and $x_{n-1}$ are comparable for all $n \in N$ due to (14), we have the following two cases.

Case 1. If $A=d\left(x_{n-1}, T x_{n}\right)+d\left(x_{n}, T x_{n-1}\right) \neq 0$, then using the contractive condition (13), we get

$$
\begin{aligned}
d\left(x_{n+1}, x_{n}\right) & =d\left(T x_{n}, T x_{n-1}\right) \\
& \leq \lambda d\left(x_{n}, x_{n-1}\right)+\mu \frac{d\left(x_{n}, T x_{n}\right) d\left(x_{n}, T x_{n-1}\right)+d\left(x_{n-1}, T x_{n}\right) d\left(x_{n-1}, T x_{n-1}\right)}{d\left(x_{n-1}, T x_{n}\right)+d\left(x_{n}, T x_{n-1}\right)} \\
& \leq \lambda d\left(x_{n}, x_{n-1}\right)+\mu \frac{d\left(x_{n}, x_{n+1}\right) d\left(x_{n}, x_{n}\right)+d\left(x_{n-1}, x_{n+1}\right) d\left(x_{n-1}, x_{n}\right)}{d\left(x_{n-1}, x_{n+1}\right)+d\left(x_{n}, x_{n}\right)} \\
& \leq \lambda d\left(x_{n}, x_{n-1}\right)+\mu \frac{d\left(x_{n-1}, x_{n+1}\right) d\left(x_{n-1}, x_{n}\right)}{d\left(x_{n-1}, x_{n+1}\right)} \\
& \leq(\lambda+\mu) d\left(x_{n}, x_{n-1}\right) .
\end{aligned}
$$


Hence, we derive that

$$
d\left(x_{n+1}, x_{n}\right) \leq h^{n} d\left(x_{1}, x_{0}\right)
$$

where $h=(\lambda+\mu)<1$. Moreover, by the triangular inequality, we have, for $m \geq n$,

$$
\begin{aligned}
d\left(x_{m}, x_{n}\right) & \leq d\left(x_{m}, x_{m-1}\right)+d\left(x_{m-1}, x_{m-2}\right)+\cdots+d\left(x_{n+1}, x_{n}\right) \\
& \leq\left(h^{m-1}+h^{m-2}+\cdots+h^{n}\right) d\left(x_{1}, x_{0}\right) \leq \frac{h^{n}}{1-h} d\left(x_{1}, x_{0}\right),
\end{aligned}
$$

and this proves that $d\left(x_{m}, x_{n}\right) \rightarrow 0$ as $m, n \rightarrow \infty$

So, $\left\{x_{n}\right\}$ is a Cauchy sequence and, since $X$ is a complete metric space, there exists $z \in X$ such that $\lim _{n \rightarrow \infty} x_{n}=z$. Further, the continuity of $T$ implies

$$
T z=T\left(\lim _{n \rightarrow \infty} x_{n}\right)=\lim _{n \rightarrow \infty} T x_{n}=\lim _{n \rightarrow \infty} x_{n+1}=z .
$$

Thus $z$ is a fixed point.

Case 2. If $A=d\left(x_{n-1}, T x_{n}\right)+d\left(x_{n}, T x_{n-1}\right)=0$, then $d\left(x_{n+1}, x_{n}\right)=0$. This implies that $x_{n}=$ $x_{n+1}$, a contradiction. Thus there exists a fixed point $z$ of $T$.

Example 16 Let $X=[0,1]$ with the usual metric and usual order $\leq$. We define an operator $T: X \rightarrow X$ in the following way:

$$
T x=\frac{2 x+3}{4\left(x^{2}+x+\frac{5}{4}\right)} .
$$

It is clear that $T$ is continuous on $[0,1]$. Now, for $\lambda=\frac{16}{25}$ and any $\mu \in[0,1)$ such that $\lambda+\mu<1$. Without loss of generality, we assume that $x \leq y$. So, we have

$$
\begin{aligned}
d(T x, T y) & =\frac{1}{4}\left|\frac{2 x+3}{x^{2}+x+\frac{5}{4}}-\frac{2 y+3}{y^{2}+y+\frac{5}{4}}\right| \\
& =\left|\frac{2 x y(y-x)+3(y-x)(x+y)+3(y-x)-\frac{5}{2}(y-x)}{4\left(x^{2}+x+\frac{5}{4}\right)\left(y^{2}+y+\frac{5}{4}\right)}\right| \\
& =\left|\frac{2 x y+3(x+y)+\frac{1}{2}}{4\left(x^{2}+x+\frac{5}{4}\right)\left(y^{2}+y+\frac{5}{4}\right)}\right||x-y| \\
& \leq \frac{16}{25}|y-x|=\frac{16}{25} d(x, y)
\end{aligned}
$$

for all $x, y \in X$. Also, there exists $x_{0}=0 \in X$ such that

$$
x_{0}=0 \leq T x_{0}
$$

is satisfied. This shows that conditions of Theorem 15 hold and $T$ has a fixed point $\frac{1}{2} \in$ $[0,1]$.

We may remove the continuity criteria on $T$ in Theorem 15 as follows. 
Theorem 17 Let $(X, d, \preceq)$ be a complete partially ordered metric space and let $T$ be a nondecreasing self-mapping defined on $X$. Suppose that a self-mapping $T$ satisfies the following condition:

$$
d(T x, T y) \leq \begin{cases}\lambda d(x, y)+\mu \frac{d(x, T x) d(x, T y)+d(y, T x) d(y, T y)}{d(y, T x)+d(x, T y)} & \text { if } A \neq 0, \\ 0 & \text { if } A=0,\end{cases}
$$

for all $x, y \in X$ with $y \preceq x$, where $A=d(x, T x)+d(y, T y)$ and $\lambda$, $\mu$ are non-negative reals with $\lambda+\mu<1$. And also suppose that $X$ has the $(O C)$ property. If there exists $x_{0} \in X$ with $x_{0} \preceq T x_{0}$, then $T$ has a fixed point.

Proof We only have to check that $z=T z$. As $\left\{x_{n}\right\} \subset X$ is a non-decreasing sequence and $x_{n} \rightarrow z \in X$, then $z=\sup \left\{x_{n}\right\}$ for all $n \in N$. Since $T$ is a non-decreasing mapping, then $T x_{n} \preceq T z$ for all $n \in \mathbb{N}$ or, equivalently, $x_{n+1} \preceq T z$ for all $n \in N$. Moreover, as $x_{0} \prec x_{1} \preceq T z$ and $z=\sup \left\{x_{n}\right\}$, we get $z \preceq T z$. Suppose that $z \prec T z$. Using a similar argument as that in the proof of Theorem 15 for $x_{0} \preceq T x_{0}$, we obtain that $\left\{T^{n} z\right\}$ is a non-decreasing sequence and $\lim _{n \rightarrow \infty} T^{n} z=y$ for certain $y \in X$. Again, using (OC), we have that $y=\sup \left\{T^{n} z\right\}$. Moreover, from $x_{0} \preceq z$, we get $x_{n}=T^{n} x_{0} \preceq T^{n} z$ for $n \geq 1$ and $x_{n} \prec T^{n} z$ for $n \geq 1$ because $x_{n} \preceq z \prec$ $T z \preceq T^{n} z$ for $n \geq 1$ as $x_{n}$ and $T^{n} z$ are comparable and distinct for $n \geq 1$.

Case 1. If $d\left(T^{n} z, T x_{n}\right)+d\left(x_{n}, T^{n+1} z\right) \neq 0$, then applying the contractive condition (16), we get

$$
\begin{aligned}
d\left(x_{n+1}, T^{n+1} z\right) & =d\left(T x_{n}, T\left(T^{n} z\right)\right) \\
& \leq \lambda d\left(x_{n}, y\right)+\mu \frac{d\left(x_{n}, T x_{n}\right) d\left(x_{n}, T^{n} z\right)+d\left(T^{n} z, T x_{n}\right) d\left(T^{n} z, T^{n+1} z\right)}{d\left(T^{n} z, T x_{n}\right)+d\left(x_{n}, T^{n+1} z\right)} \\
& \leq \lambda d\left(x_{n}, T^{n} z\right)+\mu \frac{d\left(x_{n}, x_{n+1}\right) d\left(x_{n}, T^{n} z\right)+d\left(T^{n} z, x_{n+1}\right) d\left(T^{n} z, T^{n+1} z\right)}{d\left(T^{n} z, x_{n+1}\right)+d\left(x_{n}, T^{n+1} z\right)} .
\end{aligned}
$$

Making $n \rightarrow \infty$ in the above inequality, we obtain

$$
d(z, y) \leq \lambda d(z, y)
$$

As $\lambda<1, d(x, z)=0$, thus $z=y$. Particularly, $z=y=\sup \left\{T^{n} z\right\}$ and consequently, $T z \preceq z$ which is a contradiction. Hence, we conclude that $T z=z$.

Case 2. If $A=d\left(T^{n} z, T x_{n}\right)+d\left(x_{n}, T^{n+1} z\right)=0$, then $d\left(x_{n+1}, T^{n+1} z\right)=0$. Taking the limit as $n \rightarrow \infty$, we get $d(z, y)=0$. Then $z=y=\sup \left\{T^{n} z\right\}$, which implies that $T z \preceq z$, a contradiction. Thus $T z=z$.

Now we prove the sufficient condition for the uniqueness of the fixed point in Theorem 15 and Theorem 17, that is,

$\mathrm{U}$ : for any $y, z \in X$, there exists $x \in X$ which is comparable to $y$ and $z$.

Theorem 18 Adding the above mentioned condition to the hypothesis of Theorem 15 (or Theorem 17), one obtains the uniqueness of the fixed point of $T$.

Proof We distinguish two cases. 
Case 1. If $y$ and $z$ are comparable and $y \neq z$. Now we have two subcases that are as follows:

(i) If $d(z, T y)+d(y, T z) \neq 0$, then using the contractive condition, we have

$$
\begin{aligned}
d(y, z) & =d(T y, T z) \leq \lambda d(y, z)+\mu \frac{d(y, T y) d(y, T z)+d(z, T y) d(z, T z)}{d(z, T y)+d(y, T z)} \\
& \leq \lambda d(y, z)+\mu \frac{d(y, y) d(y, z)+d(z, y) d(z, z)}{d(z, y)+d(y, z)}=\lambda d(y, z) .
\end{aligned}
$$

As $\lambda<1$, so by the last inequality, we have a contradiction. Thus $y=z$.

(ii) If $d(z, T y)+d(y, T z)=0$, then $d(y, z)=0$, a contradiction. Thus $y=z$.

Case 2. If $y$ and $z$ are not comparable, then by a given condition there exists $x \in X$ comparable to $y$ and $z$. Monotonicity implies that $T^{n} x$ is comparable to $T^{n} y=y$ and $T^{n} z=z$ for $n=0,1,2, \ldots$.

If there exists $n_{0} \geq 1$ such that $T^{n_{0}} x=y$, then as $y$ is a fixed point, the sequence $\left\{T^{n} x\right.$ : $\left.n \geq n_{0}\right\}$ is constant, and consequently $\lim _{n \rightarrow \infty} T^{n} x=y$. On the other hand, if $T^{n} x \neq y$ for $n \geq 1$. Now we have two subcases as follows:

(i) If $d\left(T^{n-1} y, T^{n} x\right)+d\left(T^{n-1} x, T^{n} y\right) \neq 0$, then using the contractive condition, we obtain, for $n \geq 2$,

$$
\begin{aligned}
d\left(T^{n} x, y\right)= & d\left(T^{n} x, T^{n} y\right) \\
\leq & \lambda d\left(T^{n-1} x, T^{n-1} y\right) \\
& +\mu \frac{d\left(T^{n-1} x, T^{n} x\right) d\left(T^{n-1} x, T^{n} y\right)+d\left(T^{n-1} y, T^{n} x\right) d\left(T^{n-1} y, T^{n} y\right)}{d\left(T^{n-1} y, T^{n} x\right)+d\left(T^{n-1} x, T^{n} y\right)} \\
\leq & \lambda d\left(T^{n-1} x, y\right)+\mu \frac{d\left(T^{n-1} x, T^{n} x\right) d\left(T^{n-1} x, y\right)+d\left(T y, T^{n} x\right) d(y, y)}{d\left(y, T^{n} x\right)+d\left(T^{n-1} x, y\right)} \\
\leq & \lambda d\left(T^{n-1} x, y\right)+\mu \frac{d\left(T^{n-1} x, T^{n} x\right) d\left(T^{n-1} x, y\right)}{d\left(y, T^{n} x\right)+d\left(T^{n-1} x, y\right)} .
\end{aligned}
$$

This implies that

$$
\begin{aligned}
d\left(T^{n} x, y\right) & \leq \lambda d\left(T^{n-1} x, y\right)+\mu d\left(T^{n-1} x, y\right) \\
& =\lambda d\left(T^{n-1} x, T^{n-1} y\right)+\mu d\left(T^{n-1} x, T^{n-1} y\right) \\
& \leq \lambda\left(\lambda d\left(T^{n-2} x, y\right)+\mu d\left(T^{n-2} x, y\right)\right)+\mu\left(\lambda d\left(T^{n-2} x, y\right)+\mu d\left(T^{n-2} x, y\right)\right) \\
& =\lambda^{2} d\left(T^{n-2} x, y\right)+2 \lambda \mu d\left(T^{n-2} x, y\right)+\mu^{2} d\left(T^{n-2} x, y\right) \\
& =(\lambda+\mu)^{2} d(x, y) .
\end{aligned}
$$

By induction we get

$$
d\left(T^{n} x, y\right) \leq(\lambda+\mu)^{n} d(x, y)
$$

Taking limit as $n \rightarrow \infty$ in the above inequality, we get

$$
\lim _{n \rightarrow \infty} T^{n} x=y
$$


as $\lambda+\mu<1$. Using a similar argument, we can prove that

$$
\lim _{n \rightarrow \infty} T^{n} x=z
$$

Now, the uniqueness of the limit gives that $y=z$.

(ii) If $d\left(T^{n-1} y, T^{n} x\right)+d\left(T^{n-1} x, T^{n} y\right)=0$, then $d\left(T^{n} x, y\right)=0$. Then

$$
\lim _{n \rightarrow \infty} T^{n} x=y
$$

Using a similar argument, we can prove that

$$
\lim _{n \rightarrow \infty} T^{n} x=z
$$

Now, the uniqueness of the limit gives that $y=z$. This completes the proof.

Remark 19 If in Theorem 15-Theorem $18 \mu=0$, then we obtain Theorem 2.1-Theorem 2.3 of $[10]$.

We get the following fixed point theorem in partially ordered metric spaces if we take $\lambda=0$ in the theorems of Section 3.

Theorem 20 Let $(X, d, \preceq)$ be a complete partially ordered metric space and let $T$ be a nondecreasing self-mapping defined on $X$. Suppose that a self-mapping $T$ satisfies the following condition:

$$
d(T x, T y) \leq \begin{cases}\mu \frac{d(x, T x) d(x, T y)+d(y, T x) d(y, T y)}{d(y, T x)+d(x, T y)} & \text { if } A \neq 0 \\ 0 & \text { if } A=0\end{cases}
$$

for all $x, y \in X$ with $y \preceq x$, where $A=d(y, T x)+d(x, T y)$ and $\mu$ is a non-negative real with $0 \leq \mu<1$. Suppose also that either $T$ is continuous or $X$ satisfies the condition (OC). If there exists $x_{0} \in X$ with $x_{0} \preceq T x_{0}$, then $T$ has a fixed point.

If $(X, \preceq)$ satisfies the condition used in Theorem 18 , then the uniqueness of a fixed point can be proved.

\section{Applications}

In this section we state some applications of the main results. The first result is the consequence of Theorem 2 .

Corollary 21 Let $(X, d, \preceq)$ be a T-orbitally complete partially ordered metric space and let $T$ be a non-decreasing self-mapping defined on $X$. Suppose that a self-mapping $T$ satisfies the following condition:

$$
\int_{0}^{d(T x, T y)} d s \leq \alpha \int_{0}^{\frac{d(x, T x) \cdot d(y, T y)}{d(x, y)}} d s+\beta \int_{0}^{d(x, y)} d s+L \int_{0}^{\min \{d(x, T x), d(y, T x)\}} d s
$$

for all distinct $x, y \in X$ with $x \preceq y$ and for $\alpha, \beta \in[0,1)$ with $\alpha+\beta<1$, where $L \geq 0$. If there exists $x_{0} \in X$ with $x_{0} \preceq T x_{0}$ then $T$ has at least one fixed point. 
Similarly, the following result is the consequence of Corollary 5 .

Corollary 22 Let $T$ be a continuous, non-decreasing self-map defined on a complete partially ordered metric space $(X, d, \preceq)$. Suppose that $T$ satisfies the following condition:

$$
\int_{0}^{d(T x, T y)} d s \leq \alpha \int_{0}^{\frac{d(x, T x) \cdot d(y, T y)}{d(x, y)}} d s+\beta \int_{0}^{d(x, y)} d s
$$

for any distinct $x, y \in X$ with $x \preceq y$, where $\alpha, \beta \in[0,1)$ with $\alpha+\beta<1$. Suppose there exists $x_{0} \in X$ with $x_{0} \preceq T x_{0}$. Then $T$ has a fixed point.

The following result is the consequence of Theorem 12.

Corollary 23 Let $(X, d, \preceq)$ be a partially ordered metric space. Let $T: X \rightarrow X$ be a nondecreasing, continuous mapping. Suppose that a self-mapping $T$ satisfies

$$
\int_{0}^{d(T x, T y)} d s \leq \alpha \int_{0}^{\frac{\alpha d(T y, y)(1+d(x, T x)]}{1+d(x, y)}} d s+\beta \int_{0}^{d(x, y)} d s+L \int_{0}^{\min \{d(x, T x), d(x, T y), d(y, T x)\}} d s
$$

for any $x, y \in X$ with $x \leq y$, and for some $\alpha, \beta \in[0,1)$ with $\alpha+\beta<1$ and $L \geq 0$. Suppose that there exists $x_{0} \in X$ with $x_{0} \preceq T x_{0}$. Then $T$ has a fixed point.

\section{Competing interests}

The authors declare that they have no competing interests.

Authors' contributions

All authors contributed equally and significantly in writing this article. All authors read and approved the final manuscript

\section{Author details}

'Department of Mathematics, International Islamic University, H-10, Islamabad, 44000, Pakistan. ${ }^{2}$ Department of Mathematics, Atilim University, Incek, Ankara 06836, Turkey. ${ }^{3}$ Department of Mathematics, COMSATS Institute of Information Technology, Chack Shahzad, Islamabad 44000, Pakistan.

\section{Acknowledgements}

The authors express their gratitude to the anonymous referees for constructive and useful remarks, comments and suggestions.

Received: 6 February 2013 Accepted: 2 May 2013 Published: 17 May 2013

\section{References}

1. Edelstein, M: On fixed points and periodic points under contraction mappings. J. Lond. Math. Soc. 37, 74-79 (1962)

2. Hardy, GC, Rogers, T: A generalization of fixed point theorem of S. Reich. Can. Math. Bull. 16, 201-206 (1973)

3. Kannan, R: Some results on fixed points - II. Am. Math. Mon. 76, 71-76 (1969)

4. Reich, S: Some remarks concerning contraction mappings. Can. Math. Bull. 14, 121-124 (1971)

5. Smart, DR: Fixed Point Theorems. Cambridge University Press, Cambridge (1974)

6. Wong, CS: Common fixed points of two mappings. Pac. J. Math. 48, 299-312 (1973)

7. Wolk, ES: Continuous convergence in partially ordered sets. Gen. Topol. Appl. 5, 221-234 (1975)

8. Monjardet, B: Metrics on partially ordered sets - a survey. Discrete Math. 35, 173-184 (1981)

9. Ran, ACM, Reurings, MCB: A fixed point theorem in partially ordered sets and some application to matrix equations. Proc. Am. Math. Soc. 132, 1435-1443 (2004)

10. Nieto, JJ, Lopez, RR: Contractive mapping theorems in partially ordered sets and applications to ordinary differential equations. Order 22, 223-239 (2005)

11. Nieto, JJ, Lopez, RR: Existence and uniqueness of fixed point in partially ordered sets and applications to ordinary differential equation. Acta Math. Sin. Engl. Ser. 23(12), 2205-2212 (2007)

12. Nieto, JJ, Pouso, L, Rodríguez-López, R: Fixed point theorems in ordered abstract spaces. Proc. Am. Math. Soc. 135 2505-2517 (2007)

13. Agarwal, RP, El-Gebeily, MA, O'Regan, D: Generalized contractions in partially ordered metric spaces. Appl. Anal. 87, 1-8 (2008)

14. Bhaskar, TG, Lakshmikantham, V: Fixed point theory in partially ordered metric spaces and applications. Nonlinear Anal., Theory Methods Appl. 65, 1379-1393 (2006) 
15. Choudhury, BS, Kundu, A: A coupled coincidence point result in partially ordered metric spaces for compatible mappings. Nonlinear Anal., Theory Methods Appl. 73, 2524-2531 (2010)

16. Hong, S: Fixed points of multivalued operators in ordered metric spaces with applications. Nonlinear Anal., Theory Methods Appl. 72, 3929-3942 (2010)

17. Lakshmikantham, V, Ćirić, LB: Couple fixed point theorems for nonlinear contractions in partially ordered metric spaces. Nonlinear Anal., Theory Methods Appl. 70, 4341-4349 (2009)

18. Ozturk, M, Basarir, M: On some common fixed point theorems with rational expressions on cone metric spaces over a Banach algebra. Hacet. J. Math. Stat. 41(2), 211-222 (2012)

19. Rouzkard, F, Imdad, M: Some common fixed point theorems on complex valued metric spaces. Comput. Math. Appl. (2012). doi:10.1016/j.camwa.2012.02.063

20. Ahmad, J, Arshad, M, Vetro, C: On a theorem of Khan in a generalized metric space. Int. J. Anal. 2013, Article ID 852727 (2013)

21. Altun, I, Damjanovic, B, Djoric, D: Fixed point and common fixed point theorems on ordered cone metric spaces. Appl. Math. Lett. 23, 310-316 (2010)

22. Amini-Harandi, A, Emami, H: A fixed point theorem for contraction type maps in partially ordered metric spaces and application to ordinary differential equations. Nonlinear Anal., Theory Methods Appl. 72, 2238-2242 (2010)

23. Arshad, M, Azam, A, Vetro, P: Some common fixed results in cone metric spaces. Fixed Point Theory Appl. 2009, Article ID 493965 (2009)

24. Arshad, M, Ahmad, J, Karapınar, E: Some common fixed point results in rectangular metric spaces. Int. J. Anal. 2013, Article ID 307234 (2013)

25. Aydi, H, Karapınar, E, Shatanawi, W: Coupled fixed point results for $(\psi, \varphi)$-weakly contractive condition in ordered partial metric spaces. Comput. Math. Appl. 62(12), 4449-4460 (2011)

26. Azam, A, Fisher, B, Khan, M: Common fixed point theorems in complex valued metric spaces. Numer. Funct. Anal. Optim. 32(3), 243-253 (2011)

27. Beg, I, Butt, AR: Fixed point for set-valued mappings satisfying an implicit relation in partially ordered metric spaces Nonlinear Anal. 71, 3699-3704 (2009)

28. Dricia, Z, McRaeb, FA, Devi, JV: Fixed-point theorems in partially ordered metric spaces for operators with PPF dependence. Nonlinear Anal., Theory Methods Appl. 67, 641-647 (2007)

29. Karapınar, E: Couple fixed point on cone metric spaces. Gazi Univ. J. Sci. 24(1), 51-58 (2011)

30. Karapınar, E, Luong, NV: Quadruple fixed point theorems for nonlinear contractions. Comput. Math. Appl. 64(6), 1839-1848 (2012)

31. Luong, NV, Thuan, NX: Coupled fixed points in partially ordered metric spaces and application. Nonlinear Anal. Theory Methods Appl. 74, 983-992 (2011)

32. Samet, B: Coupled fixed point theorems for a generalized Meir-Keeler contraction in partially ordered metric spaces. Nonlinear Anal. 74(12), 4508-4517 (2010)

33. Zhang, X: Fixed point theorems of multivalued monotone mappings in ordered metric spaces. Appl. Math. Lett. 23, 235-240 (2010)

34. Jaggi, DS: Some unique fixed point theorems. Indian J. Pure Appl. Math. 8(2), 223-230 (1977)

doi:10.1186/1029-242X-2013-248

Cite this article as: Arshad et al.: Some unique fixed point theorems for rational contractions in partially ordered metric spaces. Journal of Inequalities and Applications 2013 2013:248.

\section{Submit your manuscript to a SpringerOpen ${ }^{\circ}$ journal and benefit from:}

- Convenient online submission

Rigorous peer review

- Immediate publication on acceptance

- Open access: articles freely available online

- High visibility within the field

- Retaining the copyright to your article 